\title{
AGRICULTURAL BIOTECHNOLOGY RESEARCH FOR THE DEVELOPMENT OF EXPORT AGRICULTURE CROPS
}

\author{
Y.M.H.B. YAPABANDARA \\ Plant Tissue/Cell Culture Laboratory, Department of Export Agriculture, Matale.
}

Biotechnology can be defined simply as "those biological means used to develop process and products employing organisms or their components". biological means in relation to agriculture is tissue, cell or organ culture.

The Department of Export Agriculture handles research and development of a group of perennial crops. Many of the crops belong to the category of spices (black pepper, cardamom, clove, nutmeg, cinnamon, vanilla and betel) while some of the beverage crops (coffee and cocoa) are also included. Immediate requirement of biotechnological research for the development of export agriculture crops can be considered as micropropagation. Mass propagation of clonal plants that have been selected for higher yield with the desired qualities is one of the best commercial applications of tissue culture technology. Development of the micropropagation technique is important not only as a system for rapid multiplication but also to provide sterile cultures for cell culture, protoplast culture, cell fusion or genetic manipulation.

Many of the export agriculture crops are perennial and open pollinated and therefore seedling progenies are heterozygous populations. Conventional vegetative propagation is often difficult especially in woody species of export agriculture crops (clove, nutmeg, cinnamon etc.). Some of the export agriculture crops are dioecious such as nutmeg and papaya. Development of micropropagation system for such plants is particularly very important since currently no method is available to identify unproductive male plants before field planting. Multiplication of clonal materials through conventional vegetative propagation systems is difficult for these crops. The development of micropropagation systems for tropical tree species lags behind that for herbaceous species. Although micropropagation from juvenile plants is mostly possible, its usefulness is limited. Micropropagation of the 30-50 year old selected mother trees of export agriculture crops such as clove and nutmeg seems to be a difficult task. However, maintenance of nutmeg clonal materials as grafted plants in the greenhouse and adopting a re-grafting procedure has been shown to be beneficial for culture establishment. This procedure cannot be used for cloves since grafting is not possible.

The other type of export agriculture crops are non woody perennials (eg. black pepper, betel, cardamom, vanilla, papaya). Vegetative propagation is possible in most cases. However materials are inadequate for large scale multiplication of elite clones. The success of in vitro propagation of cardamom depends upon several factors. One of the important factors is the exact stage of development of the material. The composition of the culture medium is also an important factor. By manipulating the culture medium, about 25 fold multiplication rate could be achieved in $8-10$ weeks. 
A field trial is also established to compare the growth and yield performance of tissue cultured and vegetative materials.

Genotype variation among the regenerated plants from cell cultures (i.e. somaclonal variation) has been suggested as a useful source of potentially valuable source of variation. Somaclonal variants which are selected for different characters such as disease resistance and drought tolerance are also important for future research work. Drought tolerant export agriculture crops are required for the areas in the coconut triangle with limited rainfall. Generally regenerated plants obtained via callus phase tend to give genetic variations. The ploidy level of a plant could be changed by tissue culture without mutagens by manipulating the composition of the medium and explant. ${ }^{2}$ For example, octoploid potato could be obtained from the tetraploid potato. In addition, a broad range of aneuploidy could also be obtained through tissue culture. Potato varieties with red tuber skin colour converted to white in some instances. Alteration of the DNA sequence was also achieved although the phenotype of the materials is similar. ${ }^{2}$ For somaclonal variation and some of the transformation studies an efficient method of regeneration is a prerequisite. Among the export agriculture crops, regeneration through callus (via somatic embryogenesis) is feasible in a few crops (coffee and cocba). Therefore development of regeneration procedures from callus and cell cultures is an important area of research for the development of export agriculture crops.

In conclusion, plant biotechnology will make an important contribution for the development of export agriculture crops. Firstly more applicable biotechnological research such as in vitro clonal propagation is required. After the development of a reliable regeneration procedure from the callus, cell or protoplasts, biotechnological research can be extended to other areas such as somaclonal variation and somatic hybridization and transformation studies. The future promises optimism because the intense research activity will begin to reveal the potential rewards in more productive plant varieties.

\section{References}

1. Kinney T.B. (1986). Biotechnology in perspective. In: Biotechnology for Solving Agricultural Problems, (Eds P.C. Augustine, H.D. Danforth, M.R . Bakst). Martinus Nijhoff Publishers, pp. 1-6. Dordrecht/Boston/Lancaster.

2. Yapabandara Y.M.H.B. (1993). Factors influencing regeneration in vitro and induction of somaclonal variation in potato. $\mathrm{Ph} \mathrm{D}$. Thesis, University of Reading, U.K. 